\title{
Mechanisms of Synergistic Skin Penetration by Sonophoresis and Iontophoresis
}

\author{
Tomohiro Hikima, * Shinya Ohsumi, Kenta Shirouzu, and Kakuji Tojo \\ Faculty of Computer Science and Systems Engineering, Kyushu Institute of Technology; 680-4 Kawazu, Iizuka, Fukuoka \\ 820-8502, Japan. Received July 24, 2008; accepted January 30, 2009; published online February 23, 2009
}

\begin{abstract}
The mechanism of skin penetration enhancement by ultrasound under sonophoresis (US) or by an electrical field under iontophoresis (IP) was investigated using hairless mouse skin in vitro. The seven model chemicals with different molecular weights (122-1485) were dissolved in a hydrophilic gel. Donor gel with the chemicals was loaded on the skin surface and then the skin was treated with US $\left(300 \mathrm{kHz}, 5.2 \mathrm{~W} / \mathrm{cm}^{2}, 5.4 \%\right.$ duty-cycle) and IP $\left(0.32 \pm 0.03 \mathrm{~mA} / \mathrm{cm}^{2}\right)$ individually or with US and IP in combination (US+IP). The penetration profiles of the chemicals with a molecular weight of less than 500 were influenced by the presence of an electric charge, the profiles of ionized chemicals for US+IP were the same as profiles for IP, while the penetration flux of a non-ionized chemical synergistically increased with US+IP compared with the individual flux of US and IP. The chemicals with molecular weight of more than 1000 showed synergistic effects with US+IP. The mathematical simulation assuming a bilayer skin model revealed that the synergistic effects were mainly influenced by electroosmosis in the stratum corneum (SC). Therefore the synergistic effects of US+IP was mainly caused by the SC diffusivity of chemicals increased by US and the electroosmotic water flow by IP application.
\end{abstract}

Key words transdermal therapeutic system; iontophoresis; ultrasound; molecular weight; electric charge

Transdermal therapeutic systems have been developed by conceiving effective enhancement methods against the stratum corneum (SC) barrier function. ${ }^{1)}$ Researchers have reported a number of chemical, biochemical, and physical enhancers that increase the skin flux of drugs by different mechanisms. ${ }^{2,3)}$ These enhancers individually increase the flux in in vitro skin penetration and in vivo animal experiments, although their applications in humans are limited due to undesirable side effects. For safety, economic, and efficacy reasons, a combination of enhancers was proposed in several reports. ${ }^{4-6)}$ Previously, we reported that the ultrasound (US) and iontophoresis (IP) combination (US + IP) synergistically increased the penetration flux of a chemical with large molecular weight in vitro. ${ }^{7)}$ It was clear that US increased the diffusivity of chemicals in the SC and that IP enhanced the movement of water through the SC.

This study investigated the mechanism of the synergistic effects on skin penetration with US + IP. We performed skin penetration experiments with US and IP using seven model chemicals with different electric charges and molecular weights in vitro. Moreover, the effects of electroosmosis during IP application were simulated assuming a bilayer [SC and viable skin (VS)] skin model. ${ }^{8)}$ We discuss the effects of an electric charge and molecular weight on the synergistic enhancement by US +IP.

\section{MATERIALS AND METHODS}

Materials Female hairless mice (Kud: $\mathrm{Hr}^{-}$strain, 7 weeks old) were purchased from Kyudo Co., Ltd. (Saga, Japan). Vitamin $B_{12}$ (VB), benzoic acid (BA), hydrocortisone (HC), indomethacin (IM), and hiviswako104 were purchased from Wako Pure Chemical Industries, Ltd. (Osaka, Japan). Lidocaine hydrochloride (LH) and timolol malate (TM) were purchased from MP Biomedicals, Inc. (OH, U.S.A.) and Aldrich Chemical Company, Inc. (Tokyo, Japan), respectively. Vancomycin hydrochloride (VH) was supplied by Shionogi \& Co., Ltd. (Osaka, Japan). Other chemicals of special reagent grade were purchased from Wako Pure Chemicals Industries. The physicochemical properties of the seven model chemicals are summarized in Table 1. The molecular weight of the model chemicals used ranged from 100 to 1500 and, under those conditions, the SC controlled their skin penetration. ${ }^{9)}$ In this study, we especially paid attention to the molecular weight and electric charge of chemicals.

Hydrogel Preparation After the model chemicals were dissolved in phosphate buffer $5 \mathrm{~mm}(\mathrm{pH} 7.4)$, the buffer and hiviswako104 were thoroughly mixed. Then, triethylamine was added to adjust the gel $\mathrm{pH}$ to neutral. Each model chemical was maintained at a fixed concentration during the experiment, as listed in Table 1. Blank gel without a model chemical was also prepared as described above. The hydrogels were stored in a refrigerator at $4{ }^{\circ} \mathrm{C}$ before use.

In Vitro Skin Penetration Experiment Abdominal intact and stripped skin was excised from hairless mice. The stripped skin completely removed the SC from intact skin by adhesive tape (CT-24F, Nichiban Co., Ltd., Tokyo, Japan) stripping. The skin samples were mounted on a vertical penetration cell system (Vidrex Co., Ltd., Fukuoka, Japan) with two half moon-shaped diffusion areas $\left(2 \mathrm{~cm}^{2}\right) .{ }^{10)}$ The epidermis of the skin faced the receptor compartment $(55 \mathrm{ml})$ that was filled with phosphate buffer solution ( $\mathrm{pH} 7.4)$. The donor

Table 1. Physicochemical Properties of Model Chemicals

\begin{tabular}{ccccc}
\hline \hline Drug & $\begin{array}{c}\text { Molecular } \\
\text { weight }\end{array}$ & $\begin{array}{c}\text { Electric } \\
\text { charge at } \\
\text { pH } 7.4\end{array}$ & $\log K_{\mathrm{o} / \mathrm{w}}$ & $\begin{array}{c}\text { Drug } \\
\text { concentration } \\
\text { in hydrogel [\%] }\end{array}$ \\
\hline BA & 122 & -1 & 1.87 & 0.67 \\
LH & 270 & +1 & -3 & 4.0 \\
IM & 357 & -1 & 1.32 & $5.0 \times 10^{-2}$ \\
HC & 362 & 0 & 1.43 & $2.5 \times 10^{-2}$ \\
TM & 432 & +1 & -1 & 2.0 \\
VB & 1355 & 0 & -4.33 & 2.0 \\
VH & 1485 & +1 & $<0$ & 2.0 \\
\hline
\end{tabular}

BA, benzoic acid; LH, lidocaine hydrochloride; IM, indomethacin; HC, hydrocortisone; TM, timolol malate; $\mathrm{VB}$, vitamin $\mathrm{B}_{12}$; VH, vancomycin hydrochloride. 
Table 2. Analytical Conditions of Model Chemicals Used

\begin{tabular}{|c|c|c|}
\hline Drug & $\begin{array}{l}\text { Wavelength } \\
\quad[\mathrm{nm}]\end{array}$ & Mobile phase \\
\hline BA & 225 & $\begin{array}{l}75 \%\left(0.048 \mathrm{M} \mathrm{NaH}_{2} \mathrm{PO}_{4}+0.041 \mathrm{M} \mathrm{H}_{3} \mathrm{PO}_{4}\right) / 25 \% \\
\text { acetonitrile }\end{array}$ \\
\hline $\mathrm{LH}$ & 210 & $\begin{array}{l}85 \% 20 \mathrm{~mm} \text { phosphoric acid }(\mathrm{pH} 3.0) / 15 \% \\
\text { acetonitrile }\end{array}$ \\
\hline IM & 254 & $30 \% 50 \mathrm{~mm}$ phosphoric acid $/ 70 \%$ acetonitrile \\
\hline $\mathrm{HC}$ & 255 & $35 \%$ distilled water $/ 65 \%$ methanol \\
\hline $\mathrm{TM}$ & 294 & $\begin{array}{l}55 \%(0.1 \% \text { 1-heptanesulfonic acid sodium } \\
\text { salt }+1 \% \text { acetic acid })(\mathrm{pH} 7.2) / 45 \% \text { methanol }\end{array}$ \\
\hline $\mathrm{VB}$ & 250 & $\begin{array}{l}88 \% 10 \mathrm{~mm} \text { phosphate buffer }(\mathrm{pH} 7.4) / 12 \% \\
\text { acetonitrile }\end{array}$ \\
\hline $\mathrm{VH}$ & 210 & $\begin{array}{l}90 \% 50 \mathrm{~mm} \text { phosphate buffer }(\mathrm{pH} 7.4) / 10 \% \\
\text { acetonitrile }\end{array}$ \\
\hline
\end{tabular}

Abbreviations are indicated in a footnote of Table 1

gel $(2.0 \mathrm{ml})$ was added to one side of a gel folder on the skin and the same volume of blank gel without chemical was added to the other side. At predetermined time intervals, samples of receptor solution $(0.4 \mathrm{ml})$ were withdrawn for by HPLC assay.

All animal studies conformed to the "Principles of Laboratory Animal Care," NIH publication \#85-23, revised 1996. The mice were killed by an experienced individual.

US and IP Treatment One side of the skin was treated for $30 \mathrm{~min}$ with US (frequency, $300 \mathrm{kHz}$; intensity, $5.2 \mathrm{~W} / \mathrm{cm}^{2}$; pulse mode, $5.4 \%$ duty cycle) using a US generator Sonoion (Kagoshima Supersonic Technical Laboratory Co., Ltd., Kagoshima, Japan) and the other side was left untreated. A calorimetric method was used to evaluate the US intensity of Sonoion. ${ }^{11)}$ On the other hand, IP was applied to the skin for $1 \mathrm{~h}$ with a battery-powered (4LR44, 6.0 V) ION egg (current density, $0.32 \pm 0.03 \mathrm{~mA} / \mathrm{cm}^{2}$; LaSeine Co., Ltd., Osaka, Japan). After the donor gel and blank gel were added to each side of the gel folder, platinum electrodes with a half moon shape were placed on both gels. The electrode on the donor gel was changed by an electric charge of the chemical; the anodal electrode on the donor gel was represented as $\operatorname{IP}(+)$ and the cathodal electrode was $\operatorname{IP}(-)$.

Analytical Methods All model chemicals were assayed in the HPLC assembly LC 10A system (Shimadzu Co., Ltd., Kyoto, Japan) with four kinds of HPLC columns: a YMC Pack ODS-AM $(4.6 \mathrm{~mm} \times 150 \mathrm{~mm}$, YMC Co., Ltd., Kyoto, Japan) for BA and LC, a Wakosil II5C18RS (4.6 mmX $150 \mathrm{~mm}$, Wako Pure Chemicals Industries) for TM, a TSK gel ODS 80Ts $(4.6 \mathrm{~mm} \times 150 \mathrm{~mm}$, Tosoh Co., Tokyo, Japan) for IM and HC, and an L-column ODS (4.6 mm $\times 150 \mathrm{~mm}$, Chemical Evaluation and Research Institute, Tokyo, Japan) for $\mathrm{VB}$ and $\mathrm{VH}$. The column oven of the system kept at $40^{\circ} \mathrm{C}$. The other assay conditions are summarized in Table 2 .

\section{RESULTS}

Effects of the Application Order of IP and US The skin penetration of VB was investigated using two different treatment methods with US + IP (Table 3). Method I indicates that the skin was treated with US for $30 \mathrm{~min}$ and $\operatorname{IP}(+)$ for $1 \mathrm{~h}$ at the same time at $3 \mathrm{~h}$ from the start of the experiment. In method II, the skin was treated with US for $30 \mathrm{~min}$ at $1 \mathrm{~h}$ from the start of the experiment and $\operatorname{IP}(+)$ was applied for
Table 3. Effect of a Treatment Timing of Ultrasound and Iontophoresis on the Penetration Flux

\begin{tabular}{lcc}
\hline \hline & $\begin{array}{c}\text { Penetration flux } \\
{\left[\mu \mathrm{g} / \mathrm{cm}^{2} / \mathrm{h}\right]}\end{array}$ & $\begin{array}{c}\text { Enhancement ratio } \\
{[-]^{a)}}\end{array}$ \\
\hline Control & $1.63 \pm 0.97$ & - \\
Method $\mathrm{I}^{b)}$ & $79.02 \pm 52.33$ & 48 \\
${\text { Method } \mathrm{II}^{b)}}$ & $290.23 \pm 85.29$ & 177 \\
\hline
\end{tabular}

a) Enhancement ratio was the ratio of the flux treated with US+IP to the control flux. b) Method I and method II were described in text. Each data represents mean \pm S.D. of triplicated experiments.
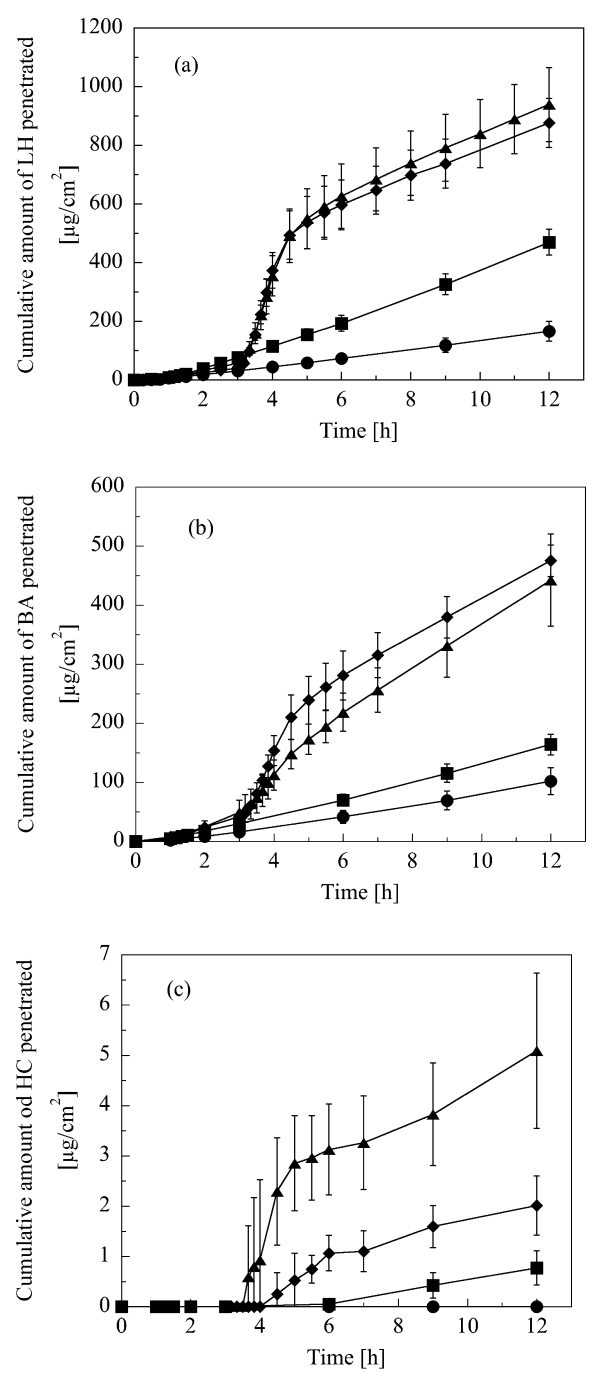

Fig. 1. Penetration Profiles of LH (a), BA (b), and HC (c)

Closed triangle, US+IP; closed diamond, IP; closed square, US; closed circle, control. Each data point is mean \pm S.D. of three experiments.

$1 \mathrm{~h}$ after a 3 -h time lag. The penetration flux in method II was 3.5-fold greater than that in method I. Thus the skin was treated with a time lag for US + IP in all experiments.

Chemicals with Molecular Weight of Less Than 500 The skin penetration was investigated for five model chemicals with a molecular weight of less than 500 and a different electric charge at $\mathrm{pH}$ 7.4; LH (Fig. 1a) and TM have a positive charge, BA (Fig. 1b), IM has a negative charge, and $\mathrm{HC}$ (Fig. 1c) is neutral. The penetration flux with individual or combination treatment is summarized in Table 4. The penetration enhancement factor of ionized chemicals for $\operatorname{IP}(+)$ or 
Table 4. Penetration Flux by Individual Treatment and Combination of Ultrasound and Iontophoresis

\begin{tabular}{lrrrr}
\hline \hline & \multicolumn{5}{c}{ Penetration flux $\left[\mu \mathrm{g} / \mathrm{cm}^{2} / \mathrm{h}\right]$} \\
\cline { 2 - 5 } Drug & \multicolumn{1}{c}{ Control } & \multicolumn{1}{c}{ US } & \multicolumn{1}{c}{ IP } & \multicolumn{1}{c}{ US + IP } \\
\hline LH & $15.03 \pm 3.05$ & $51.89 \pm 5.48$ & $437.95 \pm 84.02$ & $401.09 \pm 68.08$ \\
TM & $0.72 \pm 0.04$ & $4.05 \pm 2.52$ & $197.44 \pm 20.15$ & $380.94 \pm 57.78$ \\
BA & $11.81 \pm 1.97$ & $17.74 \pm 1.90$ & $128.45 \pm 34.06$ & $74.19 \pm 12.58$ \\
IM & $1.14 \pm 0.63$ & $1.58 \pm 0.34$ & $2.46 \pm 0.50$ & $2.16 \pm 0.27$ \\
HC & $0.06 \pm 0.04$ & $0.16 \pm 0.04$ & $0.53 \pm 0.29$ & $1.83 \pm 0.70$ \\
VB & $1.63 \pm 0.97$ & $17.59 \pm 2.85$ & $31.98 \pm 19.72$ & $290.23 \pm 85.29$ \\
VH & $0.05 \pm 0.05$ & $0.49 \pm 0.01$ & $0.31 \pm 0.04$ & $9.65 \pm 1.55$ \\
\hline
\end{tabular}

Abbreviations are indicated in a footnote of Table 1. Each data represents the mean \pm S.D. of triplicated experiments.

IP $(-)$ was almost the same value for US + IP. The penetration flux of the nonionized chemical HC for US+IP (1.83 $\mu \mathrm{g} / \mathrm{cm}^{2} / \mathrm{h}, 30.5$-fold greater than the flux of the control) was greater than that of US $\left(0.16 \mu \mathrm{g} / \mathrm{cm}^{2} / \mathrm{h}, 2.67\right.$-fold $)$ and $\operatorname{IP}(+)$ $\left(0.53 \mu \mathrm{g} / \mathrm{cm}^{2} / \mathrm{h}, 8.83\right.$-fold $)$ multiplied together. Therefore the synergistic effects of US+IP occurred only with neutral chemicals with molecular weight of less than 500 .

Chemicals with Molecular Weight of Greater Than 1000 The penetration fluxes of VB and VH are summarized in Table 4. The penetration flux of the nonionized chemical VB for US+IP (177-fold greater than that of the control) was almost the same value as the multiplication product of that for US (10.7-fold) and IP(+) (19.6-fold). The same phenomenon occurred for the ionized chemical $\mathrm{VH}$. Thus the synergistic effects of US+IP was achieved for chemicals with molecular weight of greater than 1000 irrespective of the electric charge.

\section{DISCUSSION}

SC damage was mainly caused by water absorption from the donor solution ${ }^{12)}$ and putrefaction owing to microorganisms on SC. ${ }^{13)}$ The penetration flux showed no drastic increase since the SC was barely damaged before $12 \mathrm{~h}$ after the start of an experiment (Figs. 1 to 5). This finding suggests that no SC damage occurred due to in vitro experiments.

The synergistic effects of skin penetration of VB with US + IP were previously reported. ${ }^{7)}$ The skin was treated at different timing with US and IP; the skin was pretreated with US before starting the experiment and then IP was applied as in method II. US treatment increased the diffusivity of molecules in the skin and the skin surface concentration, ${ }^{14)}$ and IP application enhanced the electroosmosis across the SC. As shown in Table 3, the synergistic effects appeared in the separate treatment (method II) and not in the simultaneous treatment (method I) with US and IP. It is therefore desirable for IP to be applied to skin pretreated with US.

The nonionized and high molecular-weight chemicals showed synergistic effects on penetration flux (Table 4). The mechanism of skin penetration enhancement by IP added electrorepulsion and electroosmosis to passive diffusion, an electroosmosis increased the flux of nonionized chemicals. ${ }^{15}$ ) To investigate the effects of electroosmosis on skin penetration, the penetration profiles of $\mathrm{LH}, \mathrm{HC}, \mathrm{VB}$, and $\mathrm{VH}$ were simulated using the penetration parameters from the separate in vitro penetration experiments and the PC software SKIN-
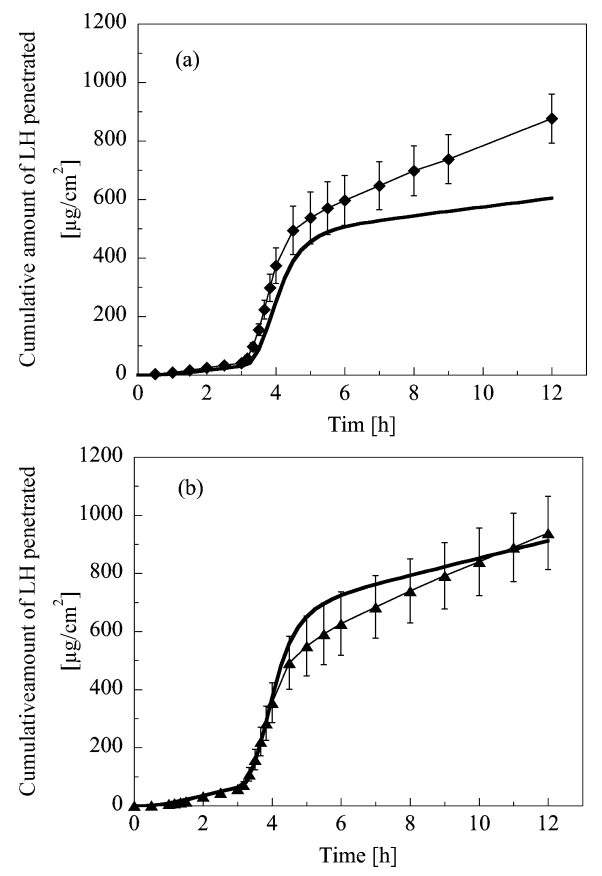

Fig. 2. Comparison between the Experimental (Plot) and Simulated Profiles (Solid Line) of LH for IP (a) and US + IP (b)

$D_{\mathrm{sc}}$ and $P_{\mathrm{e}}$ for the simulated profile in (a) were the same values as for the control $\left(D_{\mathrm{sc}}, 1.6 \times 10^{-10} \mathrm{~cm}^{2} / \mathrm{s} ; P_{\mathrm{e}}, 17.5\right)$. After treatment with US, $D_{\mathrm{sc}}^{\prime}$ increased to $3.2 \times 10^{-10} \mathrm{~cm}^{2} / \mathrm{s}$ and $P_{\mathrm{e}}^{\prime}$ decreased to 8.8 in (b). The other penetration parameters in the simulation were the thickness of whole skin $\left(L, 3.7 \times 10^{-2} \mathrm{~cm}\right)$ and $\mathrm{SC}(h$, $\left.1.0 \times 10^{-3} \mathrm{~cm}\right)$, diffusion coefficient in viable skin $\left(D_{\mathrm{ys}}, 2.4 \times 10^{-10} \mathrm{~cm}^{2} / \mathrm{s}\right)$, partition coefficient between SC and VS $\left(K_{\mathrm{sc} / \mathrm{s}}, 5.9 \times 10^{-1}\right)$, and skin surface concentration $\left(C_{\mathrm{m}}\right.$, $\left.2.6 \times 10^{4} \mu \mathrm{g} / \mathrm{ml}\right)$. Each data point is mean \pm S.D. of three experiments.

CAD assuming the bilayer (SC and VS) skin model. ${ }^{8)}$ SKIN$\mathrm{CAD}$ requires the diffusion coefficient $D$ and partition coefficient $K$ of a penetrant in the SC and VS which are evaluated from the penetration profiles of both the intact and stripped skin. ${ }^{8)}$ The degree of electroosmosis was evaluated based on the Péclet number [-] $\left(P_{\mathrm{e}}=u \times h / D_{\mathrm{sc}}\right)$ in the SC, where $u$ $[\mathrm{cm} / \mathrm{s}]$ is the convective flow rate, $h[\mathrm{~cm}]$ is the thickness of the SC, and $D_{\mathrm{sc}}\left[\mathrm{cm}^{2} / \mathrm{s}\right]$ is the diffusion coefficient in the SC. When simulating US + IP, $P_{\mathrm{e}}^{\prime}$ was calculated using $D_{\mathrm{sc}}^{\prime}$, which was determined from the penetration profile of skin treated with US. The simulated and experimental profiles are shown in Figs. 2 to 6. The parameters used for the simulation are given in each figure caption. The simulated profiles of LH agreed with the experimental profiles for both IP (Fig. 2a) and US + IP (Fig. 2b) treatments. Other chemicals with a molecular weight of less than 500 and an electric charge also showed the same phenomena (data not shown). This finding indicates that the flux of these chemicals was enhanced mainly by electrorepulsion. Therefore the synergistic effects of US + IP did not occur on chemicals influenced by electrorepulsion.

On the other hand, the simulated fluxes of $\mathrm{HC}$ enhanced synergistically by US + IP were obviously different from the experimental profiles for IP (Fig. 3a) and US+IP (Fig. 4a). The value of $D_{\text {sc }}\left(2.9 \times 10^{-12} \mathrm{~cm}^{2} / \mathrm{s}\right)$ was obtained from the penetration profiles across intact and stripped skin, and then $P_{\text {e }}$, the dimensionless convective flow, was calculated to be 967 using the parameters $h$ and $u$ of $1.0 \times 10^{-3} \mathrm{~cm}$ and $2.8 \times 10^{-8} \mathrm{~cm} / \mathrm{s}$, respectively. $\left.{ }^{14}\right)$ To fit the simulated profile of $\mathrm{HC}$ for IP to the experimental profile, the value of $P_{\mathrm{e}}$ must be 

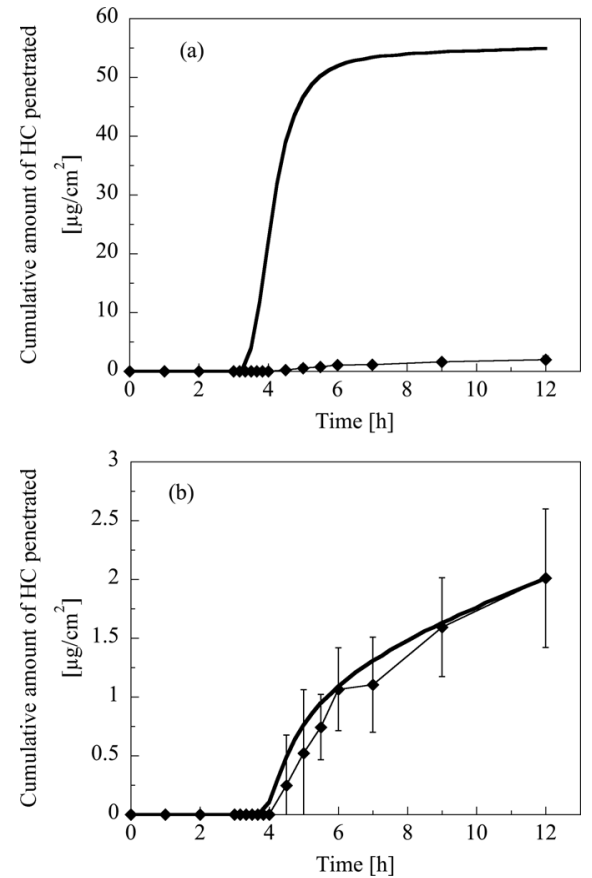

Fig. 3. Effects of $P_{\mathrm{e}}$ Value (a, 967; b, 77.4) on the Simulated Profile (Solid Line) of $\mathrm{HC}$ for IP

The value of $P_{\mathrm{e}}(967)$ was calculated using the $D_{\mathrm{sc}}$ value $\left(2.9 \times 10^{-12} \mathrm{~cm}^{2} / \mathrm{s}\right)$ determined from the control profile. $L=3.7 \times 10^{-2} \mathrm{~cm}, h=1.0 \times 10^{-3} \mathrm{~cm}, D_{\mathrm{ys}}=2.4 \times 10^{-7}$ $\mathrm{cm}^{2} / \mathrm{s}, K_{\mathrm{sc} / \mathrm{vs}}=25.1, C_{\mathrm{m}}=5.8 \times 10^{3} \mu \mathrm{g} / \mathrm{ml}$. Each data point is mean \pm S.D. of three experiments.
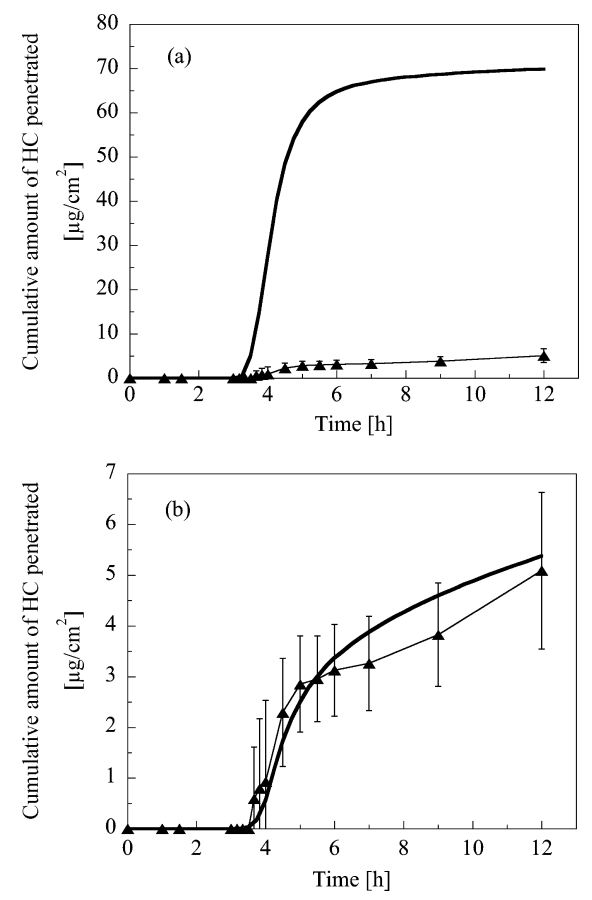

Fig. 4. Effect of $P_{\mathrm{e}}^{\prime}$ Value $(\mathrm{a}, 447 ; \mathrm{b}, 44.7)$ on the Simulated Profile (Solid Line) of $\mathrm{HC}$ for US + IP

The value of $P_{\mathrm{e}}^{\prime}(447)$ was calculated using the $D_{\mathrm{sc}}^{\prime}$ value $\left(6.3 \times 10^{-12} \mathrm{~cm}^{2} / \mathrm{s}\right)$ determined from the profile treated by US. $L=3.7 \times 10^{-2} \mathrm{~cm}, h=1.0 \times 10^{-3} \mathrm{~cm}, D_{\mathrm{vs}}=2.4 \times$ $10^{-7} \mathrm{~cm}^{2} / \mathrm{s}, K_{\mathrm{sc} / \mathrm{vs}}=31.4, C_{\mathrm{m}}=7.3 \times 10^{3} \mu \mathrm{g} / \mathrm{ml}$. Each data point is mean \pm S.D. of three experiments.
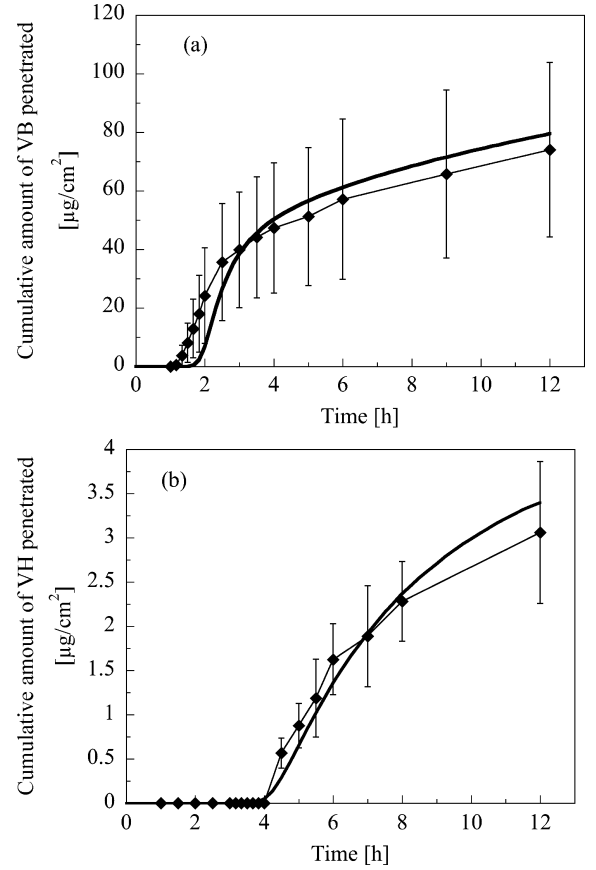

Fig. 5. Comparison between the Simulated Profile (Solid Line) and Experimental Profile (Diamond Plots) of VB (a) and VH (b) for IP Application

The $P_{\mathrm{e}}$ values of the simulated profile were decreased to $12.4 \%$ for VB $\left(P_{\mathrm{e}}=80.0\right)$ and $8.5 \%$ for $\mathrm{VH}\left(P_{\mathrm{e}}=89.0\right)$ to fit the experimental profile, respectively. $L=$ $3.7 \times 10^{-2} \mathrm{~cm}, h=1.0 \times 10^{-3} \mathrm{~cm}, D_{\mathrm{sc}}=4.4 \times 10^{-12} \mathrm{~cm}^{2} / \mathrm{s}$ for $\mathrm{VB}$ and $4.1 \times 10^{-12} \mathrm{~cm}^{2} / \mathrm{s}$ for VH, $D_{\mathrm{vs}}=2.5 \times 10^{-7} \mathrm{~cm}^{2} / \mathrm{s}$ for VB and $5.0 \times 10^{-8} \mathrm{~cm}^{2} / \mathrm{s}$ for VB, $K_{\mathrm{sc} / \mathrm{vs}}=8.2$ for VB and 2.0 for VH, $C_{\mathrm{m}}=1.1 \times 10^{5} \mu \mathrm{g} / \mathrm{ml}$ for VB and $3.5 \times 10^{3} \mu \mathrm{g} / \mathrm{ml}$ for $\mathrm{VH}$. Each data point is mean \pm S.D. of three experiments.
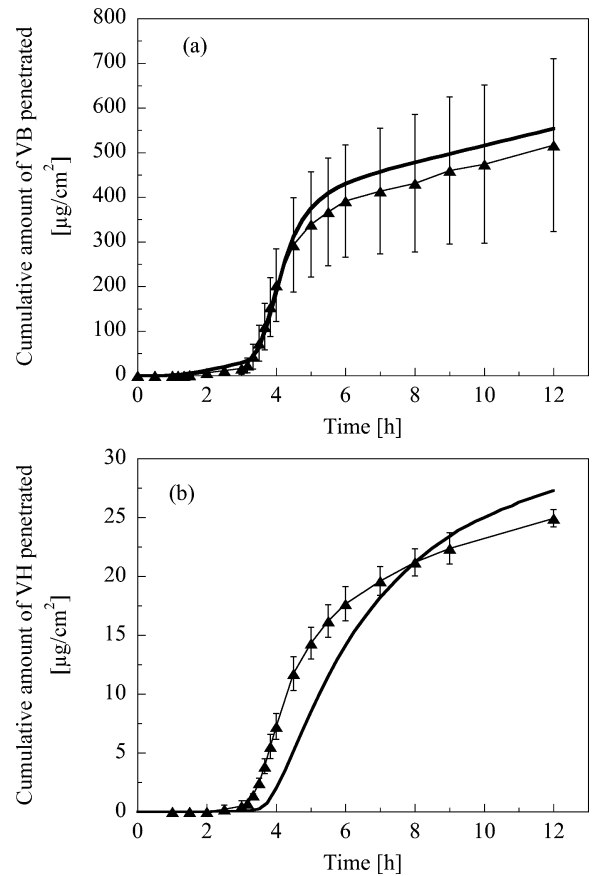

Fig. 6. Comparison between the Simulated Profile (Solid Line) and Experimental Profile (Triangle Plots) of VB (a) and VH (b) for US + IP Treatment

The $P_{\mathrm{e}}^{\prime}$ values of the simulated profile were decreased to $46.5 \%$ for $\mathrm{VB}\left(P_{\mathrm{e}}^{\prime}=20.0\right)$ and $85.0 \%$ for $\mathrm{VH}\left(P_{\mathrm{e}}^{\prime}=73.4\right)$ to fit the experimental profile, respectively. $L=$ $3.7 \times 10^{-2} \mathrm{~cm}, h=1.0 \times 10^{-3} \mathrm{~cm}, D_{\mathrm{sc}}^{\prime}=6.1 \times 10^{-11} \mathrm{~cm}^{2} / \mathrm{s}$ for VB and $3.2 \times 10^{-11} \mathrm{~cm}^{2} / \mathrm{s}$ for $\mathrm{VH}, D_{\mathrm{vs}}=2.5 \times 10^{-7} \mathrm{~cm}^{2} / \mathrm{s}$ for VB and $5.0 \times 10^{-8} \mathrm{~cm}^{2} / \mathrm{s}$ for VB, $K_{\mathrm{se} / \mathrm{vs}}=7.1$ for VB and 1.8 for VH, $C_{\mathrm{m}}=9.1 \times 10^{4} \mu \mathrm{g} / \mathrm{ml}$ for $\mathrm{VB}$ and $3.2 \times 10^{3} \mu \mathrm{g} / \mathrm{ml}$ for $\mathrm{VH}$. Each data point is mean \pm S.D. of three experiments. 
decreased to $8.0 \%\left(P_{\mathrm{e}}=77.4\right.$, Fig. $\left.3 \mathrm{~b}\right)$. This suggests that electroosmosis during IP application may be overestimated for a nonionized molecule. The value of $D_{\text {sc }}$ was increased by US treatment to $D_{\mathrm{sc}}^{\prime}\left(6.3 \times 10^{-12} \mathrm{~cm}^{2} / \mathrm{s}\right)$ and the $P_{\mathrm{e}}^{\prime}$ value was 447 (Fig. 4a). Boucaud et al. reported that the water flux for US treatment (frequency, $20 \mathrm{kHz}$; intensity, $2.5 \mathrm{~W} / \mathrm{cm}^{2}$; pulse mode, $10 \%$ duty cycle) showed an increase of 2.5 -fold in comparison with that for the control. ${ }^{16)}$ The $P_{\mathrm{e}}^{\prime}$ value decreased to $10.0 \%$ in comparison with the value of the simulated penetration profiles to fit the experimental profile $\left(P_{\mathrm{e}}^{\prime}=44.7\right.$, Fig. 4b). Chemicals with a large molecular weight also showed the same phenomena irrespective of the electric charge (Figs. 5, 6). The $P_{\mathrm{e}}$ value of nonionized VB and ionized VH decreased to $12.4 \%\left(P_{\mathrm{e}}=80.0\right.$, Fig. 5a) and $8.5 \%$ $\left(P_{\mathrm{e}}=89.0\right.$, Fig. 5b), respectively. US + IP also reduced the $P_{\mathrm{e}}^{\prime}$ value of the two chemicals to $46.5 \%$ for $\mathrm{VB}\left(P_{\mathrm{e}}^{\prime}=20.0\right.$, Fig. $6 \mathrm{a})$ and $85.0 \%$ for $\mathrm{VH}\left(P_{\mathrm{e}}^{\prime}=73.4\right.$, Fig. $\left.6 \mathrm{~b}\right)$. The amount of decrease in $P_{\mathrm{e}}$ was greater than that in $P_{\mathrm{e}}^{\prime}$. These phenomena support the hypothesis that the mechanism of enhancement by IP was mainly caused by the convective flow rate. ${ }^{17,18)}$ Thus chemicals that had increased convective flow with US treatment showed synergistic effects in skin penetration with $\mathrm{US}+\mathrm{IP}$.

\section{CONCLUSION}

The synergistic effects of US + IP treatment on the penetration flux across the skin occurred in nonionized and high molecular-weight (about 1500) chemicals. The skin was treated with US $1 \mathrm{~h}$ from the start of experiments, and then IP was applied at a $3 \mathrm{~h}$ time lag. US changed the skin structure and resulting increase in the diffusion coefficient in the SC. IP produced the additional physical forces of electrorepulsion and electroosmosis, according to the chemical struc- ture. These phenomena enhanced the movement not only of chemicals but also of water in the SC, and electroosmosis was the key factor in the synergistic effects.

\section{REFERENCES}

1) Prausnitz M. R., Mitragotri S., Langer R., Nat. Rev. Drug Discov., 3, 115-124 (2004).

2) Thong H.-Y., Zhai H., Maibach H. I., Skin Pharmacol. Physiol., 20, $272-282(2007)$

3) Williams A. C., Barry B. W., Adv. Drug Deliv. Rev., 56, 603-618 (2004).

4) Mitragotri S., Pharm. Res., 17, 1354-1359 (2000).

5) Nolan L. M. A., Corish J., Corrigan O. I., Fitzpatrick D., Int. J. Pharm., 341, 114-124 (2007).

6) Fang J.-Y., Lee W.-R., Shen S.-C., Fang Y.-P., Hu C.-H., Br. J. Dermatol., 151, 132-140 (2004).

7) Shirouzu K., Nishiyama T., Hikima T., Tojo K., J. Chem. Eng. Jpn., 42, 300-305 (2008).

8) Tojo K., "Mathematical Models of Transdermal and Topical Drug Delivery," 2nd ed., Biocom Systems Inc., Fukuoka, 2005.

9) Brown M. B., Martin G. P., Jones S. A., Akomeah F. K., Drug Deliv., 13, 175-187 (2006).

10) Miyagi T., Hikima T., Tojo K., J. Chem. Eng. Jpn., 39, 360-365 (2006).

11) Hikima T., Hirai Y., Tojo K., Pharm. Res., 15, 1680-1683 (1998).

12) Hikima T., Maibach H. I., Biol. Pharm. Bull., 29, 2270-2273 (2006).

13) Noble W. C., "Medical Importance of the Normal Microflora," Chap. 2, ed. by Tannock G. W., Kluwer Academic, Dordrecht, 1999, pp. $24-46$.

14) Wearley L. L., "Factors Affecting Reversibility of Iontophoretic Transdermal Transport," Ph.D. Thesis, Rutgers University, New Brunswick, NJ, 1989.

15) Pikal M. J., Adv. Drug Deliv., 46, 281—305 (2001).

16) Boucaud A., Garrigue M. A., Machet L., Vaillant L., Patat F., J. Controlled Release, 81, 113-119 (2002).

17) Pikal M. J., Shah S., Pharm. Res., 7, 222-229 (1990).

18) Peck K. D., Srinivasan V., Li S. K., Higuchi W. I., Ghanem A.-H., J. Pharm. Sci., 85, 781-788 (1996). 